\title{
Kebijakan Penanggulangan Bencana: Model Kesiapsiagaan Bencana Berbasis Sekolah/ Madrasah Di Provinsi Jawa Barat
}

\author{
Nanang Suparman \\ Program Studi Ilmu Administrasi Publik, Universitas Islam Negeri Sunan Gunung Djati Bandung, Indonesia
}

\begin{tabular}{|c|c|}
\hline ARTICLE INFORMATION & \multirow{11}{*}{$\begin{array}{l}\text { West java is an area that has the potential for very complex disasters. Based on the data release the regional } \\
\text { disaster management agency there have 6,607 disasters in the period 2015-2019, natural disasters in west jawa } \\
\text { including earthquakes, tsunami, landslide, flash floods, and so forth. So that, a guidelines for disaster- } \\
\text { preparedeness schools is important to avoid school from any kind of disasters. This study aims to find out and } \\
\text { analysis model disaster-preparedeness schools in west java province and relation of disasters handling. This } \\
\text { research using a qualitative method. Data collection, interviews with informants and collection of documents } \\
\text { related to the policy guidelines for safe schools from disasters. Data analysis teachniques used are from the } \\
\text { miles and Huberman models which include data reduction, data presentation, verification and conclusion. The } \\
\text { results of this research indicate that the implementation model of disaster preparedness school policy as a } \\
\text { whole has fulfilled the rules of disaster mitigation management by implementing regulations and procedures } \\
\text { from both the central and regional levels. However, judging from the basic measures, objectives, policy } \\
\text { resources and communication between organizations have not gone well so it has not been able to cope with the } \\
\text { negative impacts of disasters in the school environment. Other factors that hinder the success of the policy there } \\
\text { is a less caring attitude of the surrounding community to be involved in the disaster preparedness school } \\
\text { program. }\end{array}$} \\
\hline Received: February 11, 2021 & \\
\hline Revised: March 05, 2021 & \\
\hline Accepted: April 18, 2021 & \\
\hline Available online: April 25, 2021 & \\
\hline KEYWORDS & \\
\hline Policy, Disaster Management, School Preparedness & \\
\hline Disaster Model, West Java province. & \\
\hline CORRESPONDENCE & \\
\hline Phone: +6282111882949 & \\
\hline E-mail: n.suparman69@gmail.com & \\
\hline
\end{tabular}

\section{PENDAHULUAN}

Indonesia menempati jalur "Cincin Api" Pasifik, dimana terdapat pertemuan lempeng benua, hal itu menyebabkan aktivitas seismik tergolong tingkat tinggi. Jalur ini mempunyai gunung api aktif dengan jumlah tertinggi di dunia. Dengan keadaan seperti itu, Indonesia dinisbahkan sebagai zona berbahaya (Bev \& Katrina, 2010). Menurut rilis data otoritas leading sector kebencanaan antara tahun 2003-2013, berbagai bencana dengan jumlah 11.274 dengan tingkat kematian mencapai 174.355 orang, kerugian yang diderita sekitar Rp. 420 Triliun. Angka yang signifikan menambah beban APBN (BNPB, 2014). Belajar dari pengalaman tersebut, pemerintah dan masyarakat harus melakukan perencanaan menyambut bencana lain yang kemungkinan akan terjadi sewaktu-waktu.

Regulasi kebencanaan di Indonesia mendefinisikan penanggulangan bencana bagian dari mitigasi bencana, salah satunya mengantisipasi infrastruktur sekolah agar aman dari bencana. Model mitigasi bencana pada satuan pendidikan dinamakan Sekolah/Madarasah Siaga Bencana (SSB) dibentuk berdasarkan regulasi yang ditetapkan BNPB dalam beleid Peraturan Nomor 4 Tahun 2012 tentang Pedoman Penerapan Keselamatan Bencana Sekolah. Salah satu contoh mewujudkan SSB dengan membentuk komunitas yang terdiri dari (1) agen sosialisasi bencana (2) agen P3K (3) informasi dan komunikasi pasca bencana (Rahman \& Umam Moleong, 2018).

Sikap kesiapsiagaan adalah elemen penting dan menjadi bagian dari penanggulangan bencana, untuk mewujudkan hal tersebut diperlukan budaya inovatif, ekonomis, logis, dan berorientasi pada kebutuhan manusia (Rachmalia MNS, et.al, 2011). Entitas sekolah adalah pemangku kepentingan utama https://doi.org/10.35308/jpp.v7i1.3393 yang bertanggung jawab untuk membangun kesiapsiagaan (Ostad, T. et.al. 2012). Merujuk pada pendapat Takahashi (2012) bahwa selain sebagai sumber pengetahuan, sekolah memiliki beberapa peran strategis dalam membangun kesiapsiagaan, seperti menjadi sumber penyebaran pengetahuan kebencanaan, menjadi pusat pendidikan partisipasi bagi masyarakat, memberikan panduan praktis tentang persiapan bila terjadi, tindakan selama serta sesudah bencana. Dengan demikian, kesiapsiagaan sekolah menjadi sangat penting dalam meningkatkan kesiapsiagaan masyarakat (Sakurai, A. et.al. 2018)

Sekolah siaga bencana merupakan learning entity dengan orientasi terhadap kesigapan, kesehatan, sekaligus sensitif pada ancaman bencana, dan memiliki rencana yang matang untuk siap merespon pada pra-bencana, tanggap darurat bencana, dan pascabencana. Sekolah siaga bencana memiliki tujuan untuk pengurangan risiko bencana seperti, sekolah mengadakan fasilitas aman, sekolah mengadakan manajemen bencana, dan warga sekolah bisa hidup harmoni dengan bencana. Adapun kriteria penyelenggaraan satuan pendidikan yang siaga terhadap bencana meliputi; (a) lokasi yang aman dari bencana dan mudah diakses, (b) konstruksi bangunan yang aman dari bencana, seperti gunung berapi, gempa bumi, tsunami, dan banjir (c) desain dan pemetaan yang aman dari bencana, (d) jalur evakuasi yang aman (e) sekolah memiliki tempat berkumpul yang aman, dan (f) objek-objek yang berbahaya disekitaran dipahami siswa di Sekolah.

Provinsi Jawa Barat (PJB) termasuk pada peta daerah rawan bencana di Indonesia. Data dan Informasi tentang Bencana Indonesia BNPB mencatat bahwa selama 2015-2019,

Attribution-ShareAlike 4.0 International. Some rights reserved 
PJB telah mengalami 1732 bencana di mana bencana yang paling sering terjadi berupa longsor atau pergerakan tanah (417 insiden) dan gempa bumi (431 insiden) dengan dampak yang cukup parah mulai dari korban jiwa hingga kerusakan infrastruktur (BNPB, 2016). Jawa Barat adalah salah satu zona merah bencana nasional dimana daerah rawan bencana alam di PJB tercatat dengan pola yang berulang berupa bencana longsor, erosi, dan gempa bumi, kemudian menyusul jenis bencala lainnya. Maka dari itu, dibutuhkan suatu kebijakan penanggulangan bencana untuk upaya mitigasi bencana, tanggap darurat, respon cepat dan tepat berkolaborasi dengan sistem manajemen yang adaptif dengan karakteristik daerah terdampak bencana. Data terkait sekolah rawan bencana rawan longsor di Jawa Barat ditampilkan pada Tabel 1.

Tabel 1. Sekolah Rawan Bencana Longsor 2019

\begin{tabular}{lcccc}
\hline \multirow{2}{*}{ Kabupaten/Kota } & \multirow{2}{*}{ Jumlah } & \multicolumn{3}{c}{ Kategori } \\
\cline { 3 - 5 } & & Rendah & Sedang & Tinggi \\
\hline l.Garut & 46 & 22 & 17 & 7 \\
2.Cianjur & 25 & 11 & 6 & 8 \\
3.Bandung Barat & 19 & 9 & 12 & 8 \\
4.Bogor & 16 & 7 & 5 & 4 \\
5.Tasikmalaya & 12 & 6 & 3 & 3 \\
6.Sukabumi & 10 & 3 & 2 & 5 \\
\hline
\end{tabular}

Sumber: BPBD Jawa Barat, diolah 2019.

Data Tabel 1, menunjukan bencana longsor mengancam sekolah dengan ketegori sekolah tingkat dasar dan menengah yang pada umumnya sering terjadi di kabupaten/kota wilayah priangan timur maupun priangan barat. Kontur tanah yang labil dan kemiringan yang relatif curam menjadi penyebab sejumlah bangunan sekolah rawan longsor. Pendirian bangunan sekolah/madrasah belum mengacu pada peta zonasi rawan bencana. Longsor. Adapun data terkait sekolah rawan bencana dengan kategori bencana gempa bumi dapat dilihat pada tampilan Tabel 2.

Tabel 2. Sekolah Rawan Bencana Gempa Bumi 2019

\begin{tabular}{llccc}
\hline \multirow{2}{*}{ Kabupaten/Kota } & \multirow{2}{*}{ Jumlah } & \multicolumn{3}{c}{ Kategori } \\
\cline { 3 - 5 } & & Rendah & Sedang & Tinggi \\
\hline l.Kota Bandung & 116 & 71 & 29 & 16 \\
2.Kab. Bandung & 65 & 36 & 15 & 15 \\
3.Kab. Sukabum & 39 & 13 & 17 & 9 \\
4.Kab.Bandung & 33 & 8 & 16 & 9 \\
5.Bandung Barat & 22 & 9 & 7 & 6 \\
6.Sukabumi & 11 & 4 & 2 & 5 \\
\hline
\end{tabular}

Sumber: BPBD Jawa Barat, diolah 2019.

Bencana gempa bumi sulit diprediksi kapan akan terjadi, sesuai data pada Tabel 3, Kota Bandung terutama bagian utara banyak didirikan bangunan sekolah yang sejatinya peruntukan untuk zona hijau. Kabupaten Bandung bagian selatan juga sering mengalami gempa bumi yang mengakibatkan kerusakan infrastruktur sekolah cukup signifikan. Peta zonasi rawan gempa bumi belum menjadi acuan para pihak penanggung jawab penyelenggaraan sekolah untuk pembangunan sekolahsekolah baru atatu merelokasi sekolah-sekolah yang berulangkali tertimpa bencana gempa bumi.

Sebagai tindak lanjut PSSB, maka Pemerintah Jawa Barat menetapkan pilot project SSB untuk Tahun 2018-2019, dimana terdapat 147 Sekolah Siapsiaga Bencana Yang Tersebar di Kabupaten Sukabumi (2l sekolah), Tasikmalaya 26 sekolah, Kabupaten Garut (32 sekolah), Kabupaten Cianjur (24 sekolah), Sumedang 22 Sekolah, dan Kabupaten Ciamis 22 Sekolah yang baru dimulai pada tahun 2018. Berdasarkan data dari Inarisk, jumlah satuan pendidikan di jawa barat adalah 29.860 (dua puluh sembilan ribu delapan ratus enam puluh) satuan pedidikan. Jumlah sekolah dengan rawan bencana tingkat tinggi di Jawa Barat sebanyak 1.789 sekolah (seribu tujuh ratus delapan puluh sembilan) rawan banjir, 1.376 (seribu tiga ratus tujuh puluh enam) sekolah rawan longsor, 1977 (seribu sembilan ratus tujuh puluh tujuh) rawan gempa bumi, 38 (tiga puluh delapan) sekolah rawan tsunami, dan 9 (sembilan) sekolah rawan letusan gunung api aktif (Kemendikbud, 2019).

Penetapan sekolah siaga bencana merupakan komitmen pemerintah pusat dan daerah untuk mengatasi dampak bencana yang menimpa warga dan bangunan sekolah yang terjadi secara rutin setiap tahun. Kerusakan infrastruktur sekolah dan bahkan korban jiwa pada siswa maupun guru meningkat, pemerintah pro-aktif dalam memperbaharui manajemen aksi tanggap bencana maupun mempersiapkan dari segi anggarannya. Dengan penerbitan serangkaian regulasi baik pada tingkat pusat maupun daerah yang dimaksudkan untuk saling memperkuat koordinasi bagi aparat yang bekerja di lapangan. Disamping itu, pemerintah aktif melakukan pelatihan tanggap bencana dan sosialisasi tentang mitigasi bencana khusunya bencana yang terjadi di lingkungan sekolah. Program tanggap bencana tersebut telah memuat mekanisme alur mitigasi penyelamatan secara darurat dan didukung dengan penyediaan infrastruktur bagi perlindungan masyarakat yang terkena bencana.

Akan tetapi, pembuatan seperangkat, regulasi dan program aksi yang ditujukan untuk mengurangi sekolah dengan kategori rawan bencana belum dapat mengatasi dampak buruk bencana pada sekolah dan warga sekolah yang menjadi korban bencana. Hasil evaluasi pemerintah daerah menunjukkan angka sekolah rawan bencana justru semakin menunjukkan peningkatan. Kondisi yang diluar ekspektasi pemerintah ini terjadi karena pembangunan gedung bangunan untuk sekolah-sekolah baru tidak memperhatikan site plan zona bencana yang telah disusun pemerintah, juga pada umumnya sekolah tidak mempunyai kesigapan tanggap darurat menghadapi bencana (Zahro, et.al, 2014);(Muzenda, 2016). Hasil penelitian Amri, et al (2017) menemukan adanya sebuah sikap dan tindakan kontra produktif yang berkembang di dalam struktur pengelola sekolah pada umumnya di Indonesia. Sikap dan tindakan tersebut menganggap bencana sebagai bukan ancaman serius dan tidak sungguh-sungguh dalam mempersiapkan tindakan pencegahan dini sesuai dengan sosialisasi pemerintah yang gencar dilakukan.

Penelitian sebelumnya terkait SSB oleh Lesmana dan Purborini (2014) menunjukkan bahwa tingkat kesiapsiagaan sekolah menyongsong bencana masih rendah, pada aspek pengetahuan, sikap dan tindakan yang dilakukan komunitas SSB untuk mengurangi resiko bencana, sedangkan penelitian selanjutnya oleh Lembaga Ilmu Pengetahuan Indonesia (LIPI) menunjukkan bahwa di kota Bengkulu, Padang, kesiapsiagaan sekolah lebih rendah dari kesiapsiagaan publik dan pemerintah, dengan nilai indeks 40 (kurang siap). Ini berarti sekolah belum siap dalam menghadapi gempa bumi dan tsunami. Hasil 
penelitian ini menunjukkan kesiapsiagaan sekolah di kabupaten Mentawai, yang masih belum memadai dalam banyak aspek, terutama dibandingkan dengan kota Padang. Sementara itu, sekolah adalah ruang publik yang memiliki kerentanan tinggi terhadap bencana (CDE, 2011)

Kondisi perbedaan sikap dan tindakan antara pemerintah dan para pihak yang berkepentingan dengan status sekolah aman dari bencana dengan mitigasi dan kesiapsiagaan bencana seperti diuraikan di atas, maka peneliti tertarik untuk mendalami fenomena kesiapsiagaan terhadap kebencanaan yang terjadi, untuk itu peneliti menggunakan pisau analisis berupa teori implementasi kebijakan yang relevan dan kompatibel dalam menganalisis masalah tersebut, teori Van Metter dan Van Horn (1975) yang memiliki enam dimensi diantaranya; (l) ukuran-ukuran dasar dan tujuan-tujuan kebijakan, (2) sumber-sumber kebijakan, (3) karateristik badan-badan pelaksana, (4) komunikasi antar organisasi, (5) sikap kecenderungan pelaksana, (6) kondisi social, ekonomi, dan politik. Implementasi kebijakan sebagai instrumen hukum administrasi publik sejatinya berkekuatan untuk "memaksa" masyarakat mengikuti regulasi yang ditetapkan pemerintah demi kebaikan masyarakat itu sendiri (Winarno, 2007) Berdasarkan uraian latar belakang masalah di atas, maka rumusan masalah dalam penelitian ini adalah "Bagaimana model implementasi kebijakan penanggulangan bencana yang dilakukan pemerintah Jawa Barat berbasis sekolah/madrasah siaga bencana?". Sedangkan penelitian ini bertujuan untuk menganalisis kebijakan penanggulangan bencana dengan model implementasi sekolah/madrasah siaga bencana di Jawa Barat.

\section{METODE}

Metode dalam penelitian ini menggunakan pendekatan kualitatif yang menghasilkan data deskriptif. Pemilihan metode tersebut untuk menjawab masalah penelitian yang diajukan (Moleong, 1998), yang dalam konteks penelitian ini lebih ditekankan untuk (i) memahami proses implementasi kebijakan penanggulangan bencana untuk sekolah aman dari bencana di Jawa Barat. (ii) membangun kejelasan tentang alasan-alasan terjadi ketidakefektifan pelaksanaan program sekolah siapsiaga bencana. Sumber data penelitian menggunakan dua jenis yaitu, data primer dan data skunder. adapun data primer berupa data yang dikumpulkan dari peristiwa atau fenomena yang terjadi dan dapat diamati oleh peneliti. Sedangakan data sekunder berupa data yang diperoleh dari dokumen laporan tahunan kebencanaan Badan Penanggulangan Bencana Daerah Provinsi Jawa Barat 2019, Dokumen dari Kementrian Pendidikan dan Kebudayaan Republik Indonesia tahun 2019, dan studi pustaka seperti jurnal atau karya ilmiah dari penelitian sebelumnya. Teknik pengumpulan data penelitian melalui obeservasi, wawancara dari informan yang terdiri dari pejabat struktural BPBD Jawa Barat, yang berjumlah 11 orang yakni 1 orang pejabat Kepala Pelaksana, 1 orang pejabat Sekretaris, 3 orang pejabat Kepala Bidang dan 6 orang pejabat Kepala Seksi dan dokumen yang dilakukan langsung pada kantor Badan Penanggulangan Bencana Daerah Provinsi Jawa Barat.

Keabsahan data (trustworthiness) dari penelitian mengenai kebijakan penanggulangan bencana berbasis sekolah/madrasah di Provinsi Jawa Barat merupakan unsur penting, artinya keaslian data merupakan salah satu langkah awal kebenaran dari analisis data dimana harus berjalan seiring dengan proses penelitian yang berlangsung pada BPBD Jawa Barat. Keabsahan data kualitatif dilakukan sejak awal mulai dari pengambilan data, melakukan reduksi data, penyajian data, dan penarikan kesimpulan atau verifikasi. Untuk memperoleh keabsahan data dalam penelitian kualitatif dilakukan dengan triangulasi data, memperpanjang masa observasi, dan mengadakan member check (Miles dan Huberman,1992)

\section{HASIL DAN PEMBAHASAN}

Bencana alam menjadi kejadian rutin siklus per tahun termasuk di wilayah Jawa Barat silih berganti diterjang gempa bumi, tanah longsor, banjir bandang, tsunami dan banjir rob air laut (Mukminin, 2019). Mengatasi dampak Dampak bencana turut menimpa warga dan infrastruktur satuan pendidikan sekolah maupun madrasah dengan taksiran kerugian pada Tahun 2016 sebesar Rp. 112 Miliar, pada 2017 mencapai Rp.87 Miliar dan Tahun 2018 sebesar 127 Miliar (BPBD Jabar, 2019). Pemerintah mebuat model mitigasi bencana, melalui Peraturan Kepala Badan Nasional Penanggulangan Bencana No 04 tahun 2012 tentang Pedoman Penerapan Sekolah/Madrasah Siaga Bencana (SSB). Dalam rangka mengkaji lebih dalam bagaimana model implementasi mitigasi bencana pada satuan pendidikan di Jawa Barat dilakukan. Penjelasan hasil masing-masing dimensi diuraikan sebagai berikut

\section{Ukuran dasar dan tujuan kebijakan}

Implementator mitigasi bencana dan para pelaksana (Stakeholders) dari BPBD baik itu dari Sub bagian Pencegahan dan Kesiapsiagaan atau dari Kepala Seksi Rehabilitasi menyamakan persepsi pentingnya mitigasi bencana untuk satuan pendidikan dengan merujuk pada regulasi yang ditetapkan menjadi kebijakan yang bertujuan untuk pengurangan risiko bencana yang mengacu pada tiga pokok pelaksanaan seperti sekolah menerapkan fasilitas aman (bangunan tahan gempa), sekolah mengadakan manajemen bencana (edukasi mitigasi bencana), dan warga sekolah bisa hidup harmoni dengan bencana (ada jalur evakuasi, dan penguatan lereng gunung) di Jawa Barat pada lingkup pendidikan (sekolah/madrasah)

Terkait pemahaman terhadap latar belakang pelaksanaan kebijakan oleh para pelaksana, seorang informan mengutarakan: "Mitigasi bencana pada lingkup satuan pendidikan baik untuk sekolah umum maupun untuk madrasah memerlukan model yang berbeda dengan mitigasi pada umumnya, model penerapan sekolah/madrasah siaga bencana (SMSB) adalah upaya yang dilakukan terkait pengurangan risiko bencana pada lingkungan pendidikan (Sekolah/Madrasah) pada kabupaten/kota di Jawa Barat yang dapat dipahami oleh masyarakat luas sebagai mitigasi bencana (Pra-bencana)". (Kepala BPBD Jawa Barat, Rabu 22 April 2020, Pukul 10.30 di Kantor BPBD Jabar). Kemudian kebijakan ini menerapkan standarisasi/pedoman untuk ketentuan-ketentuan keamanan dan keselamatan warga sekolah (kepala sekolah, guru, dan siswa/siswi) supaya sekolah menjadi siaga bencana (SMSB), seperti menyebarluaskan program SMSB (Sosialisasi), serta kolaborasi dalam format kerjasama kelembagaan, akademisi, pengusaha, dan unsur media.

Dengan demikian tujuan utama diterbitkannya kebijakan sekolah sispsiaga bencana di Provinsi Jawa Barat ini adalah untuk memitigasi serta menyelamatkan warga dan infrastruktur sekolah/madrasah dari dampak bencana dengan langkah antisipatif termasuk evakuasi dari bencana. Oleh sebab itu ukuran-ukuran dasar pencapaian program berupaya 
mengidetifikasi kemampuan untuk meningkatkan tindakan pada fase pra-bencana, terjadi bencan a, dan pasca bencana.

\section{Sumber-sumber kebijakan}

Regulasi kebencanaan sebagai payung hukum dalam menentukan strategi dan implementasi penanganan dampak bencana merupakan syarat mutlak yang harus diwujudkan baik secara politis maupun birokratis. Penegasan Edwards III (1980) bahwa implementasi kebijakan dapat berjalan normal apabila tersedianya sumber-sumber yang terdiri dari sumber daya manusia dari jabatan staf hingga level pimpinan.

Dalam konteks operasional penelitian ini, hasil pengamatan mencatat bahwa BPBD sebagai leading sector yang dibentuk oleh pemerintah selama periode tertentu tidak bisa menjalankan pelaksanaan kebijakan penanggulangan bencana pada sekolah/madrasah, sehingga pemerintah daerah Provinsi Jawa Barat melakukan upaya penguatan peran institusi melalui Peraturan Gubernur no 88 tahun 2020 tentang pedoman penyelenggaraan Program Satuan Pendidikan Siaga Bencana (PSSB) dimana secara khusus isi kebijakannya tentang pengadaan fasilitas pendukung kesiapsiagaan bencana pada satuan pendidikan (Sekolah/Madrasah) yakni item yang wajib tersedia pada sekolah siaga bencana yang mencakup sarana medis (UKS), Kotak P3K diisi obat-obatan, berbagai tanda petunjuk darurat, sarana perlengkapan evakuasi, alat peringatan dini bahaya, dan peta jalur evakuasi. Dengan adanya pergub diharapkan program penerapan sekolah/madrasah siaga bencana (SSB) ini menjadi skala prioritas pada sekolah-sekolah rawan bencana. Selain itu adanya penguatan melalui peraturan gubernur secara umum sebagai penguat akan budaya siaga bencana di lingkungan sekolah sebelum pergub 88 tahun 2020 ditetapkan.

Perjalanan model penanggulangan bencana berbasis sekolah/madrasah relatif panjang hingga saat ini hampir mencapai sepuluh tahun, secara kronologis terjadi perubahan istilah yang diadopsi oleh berbagai lembaga atau instansi pemerintah dan non pemerintah. Dengan nomenklatur yang berbeda, tidak berarti sasaran program keluar dari konteks untuk menyelamatkan jiwa warga sekolah terutama anak-anak dari ancaman bencana. Terdapat sejumlah akronim yang dikenal masyarakat diantaranya: Pengurangan Risiko Bencana Berbasis Sekolah (PRBBS), Sekolah Siaga Bencana (SSB), Sekolah Aman Bencana (SAB), Sekolah/Madrasah Aman Bencana (SMAB), dan Satuan Pendidikan Aman Bencana (SPAB). Adapun dalam penelitian ini mengacu pada istilah Sekolah/Madrasah Siaga Bencana (SMSB).

Terkait adanya faktor dukungan implementasi kebijakan penyelenggaraan pengurangan risiko bencana di lingkup pendidikan dari hasil jawaban dalam wawancara dengan Sub bagian pencegahan dan kesiapsiagaan, diperoleh penjelasan sebagai berikut: "Jelas rujukan itu, diinisiasi oleh peraturan mentri dimana proses perumusannya memperhatikan aspirasi komunitas pendidikan terutama yang di daerah, dan yang sangat penting adanya fakta yang kuat kejadian bencana terus berulang dan semakin meningkat." (Kasubag Pencegahan dan Kesiapsiagaan, Kamis, 17 juni 2020 Pukul 14.25 di Kantor BPPD). Selain melakukan pelaksaaan kebijakan Badan Penanggulangan Bencana Daerah Jawa Barat memiliki aplikasi Infografis-Indeks Risiko (inaRISK) yang bisa di akses oleh masyarakat untuk mengetahui pemetaan daerah rawan bencana, jenis-jenis bencana alam di jawa barat, dan data-data sekolah rawan bencana yang telah melaksanakan SMAB.
Gambar : Aplikasi inaRISK

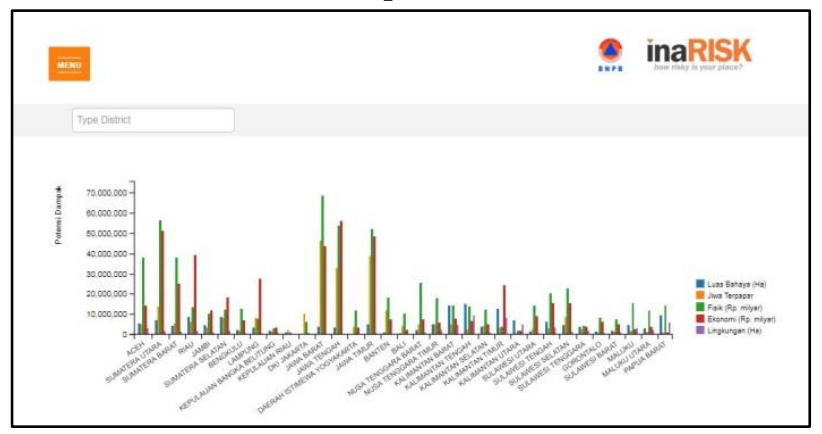

Sumber : http://inarisk.bnpb.go.id/infografis

Adapun implementasi kebijakan sangat membutuhkan sumber-sumber kebijakan lainnya, seperti adanya ketersediaan dana atau insentif dan sumber daya manusia untuk keberhasilan proses implementasi pedoman penerapan Sekolah/Madrasah Siaga Bencana (SMSB) di Jawa Barat, berdasarkan hasil wawancara dengan beberapa informan dari sub bagian pencegahan dan kesiapsiagaan BPBD diatas, penulis menemukan pemahaman terkait adanya dana dan insentif diperuntukan untuk bonus dan dorongan motivasi para pelaksana (sumber daya manusia) terhadap percepatan serta mempermudah keberhasilan program. Dalam kebijakan ini, pemerintahan daerah telah mengalokasikan anggaran lainnya melalui peraturan gubernur no 88 tahun 2020 tentang pedoman penyelenggaraan satuan pendidikan aman bencana. Adapun dana terkait lainnya seperti dana bantuan operasional sekolah (BOS), Dana Alokasi Khusus (DAK), Lembaga usaha, Dana LSM (Lembaga swadaya masyarakat), dan dana lembaga internasional (PBB, dan Bank dunia) dapat dialokasikan untuk kegiatan SPSB di sekolah diantaranya: dana bantuan operasional sekolah (BOS), Contoh kegiatan yang didanai oleh bantuan operasional sekolah (BOS), sesuai dengan juknis penggunaan dana BOS untuk pendidikan dan atau untuk kegiatan ekstrakulikuler yang sesuai dengan kebutuhan sekolah. Seperti sekolah mengundang fasilitator SMSB dari BPBD terkait, Damkar sebagai narasumber pertolongan pertama pada api, dan PMI untuk meningkatkan keterampilan pertolongan pertama pada korban. Selain pengadaan dana atau insentive pelaksanaan sekolah/madrasah aman bencana (SMSB) juga melibatkan lembaga-lembaga terkait lainnya untuk menjadi agen pelaksana (sumber daya manusia) seperti Forum Pengurangan Resiko Bencana (FPRB) jabar, Save The Children Kota Bandung, Pramuka, PMR, dan BASARNAS pada saat tanggap darurat bencana. Sebagai gambaran jumlah anggaran BPBD Jawa Barat untuk pemberdayaan masyarakat tangguh bencana Tahun 2016 sebesar Rp. 540.000.000, termasuk di dalamnya untuk program sekolah tanggap bencana.

\section{Karakteristik badan pelaksana}

Upaya yang dilakukan oleh pemerintah daerah dengan BPBD Provinsi Jawa Barat pembentukan Sekertariat Bersama (Sekber) sebangai faktor pendukung dalam mengoordinasikan penyelenggaraan program SMSB, Adapun keanggotaan Sekber tersebut diantaranya: (1) Gubernur, (2) Sekertariat daerah, (3) Perangkat daerah yang menyelenggarakan sub urusan kebencanaan (seperti BPBD,Dinas Pendidikan dan lembagalembaga terkait) dan (4) Serta perangkat daerah terkait lainnya. 
Berdasarkan Peraturan Gubernur no 88 tahun 2020 terkait dengan pengadaan Sekretariat Bersama (Sekber) SPSB sebagai tugas gubernur dalam mengkoordinir penyelenggaraannya. Adapun tugas Sekber sebagai berikut: (1) Antisipasi pra bencana yang dikoordinasikan oleh perangkat daerah yang melaksanakan pemerintahan bidang pendidikan, (2) pengkoordinasikan pelaksaan rencana aksi daerah program, (3) melakukan pendampingan teknis penyelenggaraan program (4)Menyusun laporan perkembangan penyelenggaraan program, (5) berkoordinasi dengan Sekretariatan Nasional dan (6) melaporkan kemajuan penyelenggaraan program kepada Gubernur. Adapun faktor yang menjadi penghambat implementasi pedoman penerapan sekolah/madrasah aman dari bencana di provinsi jawa barat diantaranya; (1) akses menuju lokasi sekolah/madrasah siaga bencana di kabupatenkabupaten yang sulit terjangkau, (2) terbatasnya anggaran pelaksanaan SMSB terkait dengan pengadaan fasilitas aman (bangunan tahan gempa) dari segi material bangunan, (3) Kebijakan pedoman siaga dilakukan tidak berulang-ulang (4) responsivitas orang tua/wali murid yang kurang aktif.

Berkaitan dengan karakteristik badan pelaksana memberikan penjelasan bahwa dalam pelaksanaan kebijakan peran struktur birokrasi sangat berpengaruh seperti karakteristik badan pelaksana yang mendukung atau menolak kebijakan, adanya pola-pola dan hubungan yang terjadi secara berulang-ulang untuk pelaksanaan kebijakan, serta keterkaitan badan-badan pelaksana untuk berperan dalam system penyampaian kebijakan. Review baik dari Sub Bagian Pencegahan dan Kesiapsiagaan serta dari Kepala Seksi Rehabilitasi BPBD terkait dengan peran birokrasi yang ada di jawa barat melibatkan seluruh stakeholder terkait dengan pemerintahan daerah (Gubernur), dan badan-badan pelaksana (BPBD, Disdik, Basarnas, save the children, FPRB dan organisasi terkait lainnya). Dalam penerapan kebijakan ini mengacu pada pola-pola hubungan (Koordinasi organisasi) seperti (1) memberdayakan peran kelembagaan (Kerjasama dengan internal), (2) mengintegrasikan aktivitas internal atau ekstrakulikuler, contohnya seperti pada siswa dan siswi di sekolah/madrasah yang sedang belajar geografi mereka juga dikenalkan dengan materi pembelajaran proses letusan gunung berapi dan dampak bencananya, banjir bandang dan dampak bencananya dan lain-lain.

Faktor pendukung adanya implementasi kebijakan pedoman penerapan sekolah/madrasah siaga bencana berupa muatan-muatan materi kebencanaan dan adanya simulasi terkait tanggap darurah (saat bencana terjadi) bisa masuk pada jam pelajaran tambahan khusus sekolah/madrasah yang rawan bencana, seperti yang di lakukan pada sekolah Taruna Bakti Bandung yang berada di jalan Riau Kota Bandung, yang mengadakan pendidikan terkait penerapan sekolah aman bencana yang diinisiasi oleh pihak sekolah yang membuat acara tentang bencana dan disimulasikan serta melibatkan SD, SMP, SMA, komite sekolah, pegawai staff, dan kepala sekolah. fokus kegiatannya terkait dengan bagaimana menghadapi gempa bumi yang mana Kota Bandung ini memang berdekatan atau daerah yang terdampak dari akibat sesar Lembang. Sekolah/madrasah aman bencana (SMSB) sejak 20 juni 2013, berdasarkan Koordinasi BNPB, Kementerian Agama, Kementrian Dalam Negeri, Kementrian Pekerjaan Umum, dan Kementrian Kesehatan, membuat kesepakatan terkait mitigasi bencana berbasis sekolah.
Adapun faktor penghambat implementasi kebijakan pedoman penerapan Sekolah/Madrasah Siaga Bencana (SMSB) di Provinsi Jawa berdasarkan hasil wawancara dengan informan kunci yakni Pelaksana Harian BPBD Jawa Barat dengan keterangan diantaranya: (1) terbatasnya sumber daya pelaksana kebijakan, dan masih terdapat yang tidak melakukan kegiatan berkelanjutan terkait pelaksanaannya, (2) lingkup Jawa Barat yang memang luas membutuhkan anggaran yang tidak sedikit, (3) organisasi-organisasi penggiat kebencanaan atau yang konsen pada program yang masih sedikit dan (4) penyelenggaraan program tidak dilakukan oleh sumberdaya yang tidak kompeten, tetapi harus pada sumber daya pelaksana yang sudah memiliki kompetensi dan pengalaman. (5) masih terdapat birokrasi yang berbelit-belit pada pelaksana kebijakan ketika dilapangan.

\section{Komunikasi antar organisasi dan kegiatan pelaksana}

Komunikasi antarorganisasi dan kegiatan-kegiatan pelaksana implementasi kebijakan adanya bentuk hubungan atau kerjasama yang baik antar instansi, yang ada kaitannya dengan koordinasi untuk keberhasilan suatu program tersebut, supaya terhindar dari miskomunikasi dalam hal apapun apalagi terkait penyampaian kebijakan yang akan diberlakukan. Berdasarkan data hasil wawancara dengan informan Sub bagian dan kesiapsiagaan bahwa Kolaboratif kerjasama antar lembagalembaga pemerintahan, seperti Disdik, Dinsos, kementrian PUPR, SATPOL PP, Dinas Pemadam Kebakaran dan organisasiorganisasi kemasyarakatan seperti NGO, save the children, dan Pramuka. Dalam implementasi kebijakan para pelaksana melakukan kebijakannya berpijak pada tuntunan perundangan. Terkait dengan cara melakukan koordinasi, jawaban dalam wawancara dengan Kasubbag Kesiapsiagaan diperoleh klarifikasi sebagai berikut:" Biasanya kita kirim surat edaran, serta melaukan sosialisasi SMSB terlebih untuk rencana aksi penerapan SMAB di sekolah-sekolah yang memang rawan bencana. Contohnya seperti pada Sekolah Luar biasa Negeri (SLBN) di Garut yang dilaksanakan pada 22 November 2016, selain mereka melakukan pembelajaran terkait mitigasi di sekolah dan simulasi, pihak sekolah melakukan pembentukan Kelompok siaga Bencana Sekolah Luar Biasa (KSBS) Negeri B Garut yang beranggotakan gugu-guru, komite sekolah, staf sekolah dan Kepala Sekolah.”.

Para pelaksana program SMSB non pemerintah dalam berkoordinasi melalui pengadaan latihan gabungan yang diadakan oleh Badan pelaksana dengan tujuan menyampaikan informasi SMSB di kalangan para pelaksana kebijakan. Faktor pendukung dalam menginformasikan program pedoman penerapan sekolah/madrasah siaga bencana selain dengan surat edaran kegiatan, juga dengan mempublikasikan lewat kampanye SMSB bersama organisasi-organisasi non pemerintahan. Adapun faktor penghambat dalam memberikan informasi ke sekolah berdasarkan hasil wawancara dengan kepala seksi rehabilitasi memberikan pendapat, "Memang kita harus berkoordinasi terlebih dahulu dengan dinas-dinas pendidikan baik kota atau kabupaten, akan tetapi ada yang merespon perizinannya secara cepat ada juga yang memberikan izin secara lambat sebelum peraturan gubernur no 88 tahun 2020 ini di keluarkan". 


\section{Kecenderungan pelaksanaan dan kondisi sosial ekonomi}

Adapun Kecenderungan pelaksanaan atau disposisi yang ada kaitannya dengan pemahaman tentang kebijakan sekolah/madrasah siaga bencana penulis menemukan data dari hasil wawancara dengan sub bagian pencegahan dan kesiapsiagaan serta ketua seksi rehabilitasi yang menjelaskan bahwa dalam pelaksanaan program ini tidak harus dijalankan oleh pemerintah saja tetapi unsur-unsur pelaksana seperti organisasi non pemerintah juga bisa tergabung pada pelaksanaan program SMSB di sekolah, antusias para pelaksana memang sangat tinggi seperti halnya dengan sikap dari satuan relawan dinas kebakaran Kota Bandung, forum pengurangan resiko bencana Kota Bandung, dan relwan serta masyarakat turut serta untuk pelaksanaan SMSB, adanya faktor pendukung dari sikap dan tanggapan para pelaksana kebijakan sekolah/madrasah siaga dari bencana (SMSB) memberikan upaya-upaya seperti, (1) pada saat melakukan kegiatan di sekolah, mereka terlebih dahulu harus taat berkoordinasi dengan dinas-dinas pendidikan terkait yang ada di kota atau kabupaten-kabupaten, (2) adanya pedoman terkait dengan pelaksanaan mereka mendahulukan sosialisasi dan diakhiri dengan simulasi pembelajarannya, (3) pada saaat melaksanakan kegiatan, mereka juga melibatkan unsur pendukung seperti partisipasi masyarakat dan pihak-pihak terkait lainnya. (4) adapun anggaran yang dipergunakan untuk kegiatan mereka menggunakan dana orgaisasi sendiri dan anggaran donasi perusahaan terkait. Dan selanjutnya ada faktor penghambat pelaksanaan SMSB seperti terbatasnya anggaran dari pemerintah pusat maupun daerah, program SMSB yang dilakuakan belum terebar secara merata terutama di kabupaten-kabupaten di Jawa Barat.

Realitas kehidupan dalam perspektif ekonomi, sosial, dan politik dalam pelaksaan suatu program memang berpengaruh juga pada program sekolah/madrasah siaga bencana yang harapan besarnya bisa menyadarkan warga sekolah sadar akan bahaya bencana dan membudayakan sekolah aman bencana. Setelah penulis melakukan wawancara dengan Bapak Asep Wahidin selaku koordinator pusat pengendali operasi yang mengatakan bahwa adanya pengaruh kuat dari para siswa dan siswi untuk bisa selamat ketika terjadi bencana, antusias merekapun sangat tinggi untuk bisa mengikuti pelatihanpelatihan manajemen bencana ketika dilaksanakan oleh BPBD. Penerapan pembelajaran yang menjadi prosedur BPBD terkait pelaksaan kegiatan diantaranya, pertama mengadakan dan memasang jalur evakuasi ketika terjadi bencana, kedua Menyusun sekenario simulasi ketika terjadi bencana, ketiga metetapkan jadwal simulasi, keempat mengidentifikasi kebutuhan simulasi, kelima memberikan arahan-arahan manajemen darurat bencana agar warga sekolah dapat mengurangi rasa takutnya, keenam simulasi pembelajaran ini dilakukan dengan warga sekolah serta berkelanjutan. Dan pada prinsipnya program kebijakan yang relatif kompleks memang tidak mudah dilaksanakan oleh satu lembaga saja, maka keterlibatan pemerintah daerah lewat Peraturan Gubernur menjadi penguat bahwa pengurangan resiko bencana di lingkungan sekolah harus diterapkan. Adapun faktor pendukung dan faktor penghambat terhadap pelaksanaan kebijakan sekolah/madrasah siaga bencana diantaranya, pertama faktor pendukung seperti mengadakan dan memasangkan jalur evakuasi di sekolah, menyusun skenario simulasi ketika terjadi bencana, mengidentifikasi kebutuhan simulasi, memberikan arahan-arahan manajemen darurat bencana agar warga sekolah dapat mengurangi rasa takutnya, dan simulasi pembelajaran ini dilakukan dengan warga sekolah serta berkelanjutan. Kedua adanya faktor peghambat seperti, adanya respon dari masyarakat yang memiliki ekonomi menengah kebawah tidak begitu antusias dan ada kecenderungan tidak begitu peduli terhadap pelaksanaan SMSB di sekolah, prioritas masyarakat di daerah Jawa Barat pada masyarakat menengah kebawah lebih memprioritaskan faktor kebutuhan ekonomi untuk sehari-hari, dan akses informasi yang belum merata.

\section{KESIMPULAN}

Penelitian ini bertujuan untuk menganalisis kebijakan penanggulangan bencana dengan model implementasi sekolah/madrasah siaga bencana di Jawa Barat aspek-aspek yang dianalisis antara lain ukuran dasar dan tujuan kebijakan, sumber-sumber kebijakan, komunikasi antar organissi, karakteristik badan pelaksana, kecenderungan pelaksanan, dan kondisi sosial, ekonomi politik. Data primer penelitian ini adalah hasil wawancara dengan pejabat BPPD Jawa barat dan Dokumen-dokumen otentik. Metode analisis yang digunakan adalah kualitatif-deskriptif.

Hasil penelitian menyimpulkan bahwa model implementasi kebijakan sekolah siaga bencana secara keseluruhan sudah memenuhi kaidah penanganan mitigasi bencana dengan menerapkan regulasi dan prosedur-prosedur baik dari tingkat pusat maupun daerah. Namun, dilihat dari ukuran-ukuran dasar dan tujuan-tujuan kebijakan sekolah/madrasah siaga bencana (SMSB) di Jawa Barat masih belum berjalan dengan baik, terbukti bahwa lambatnya penguatan regulasi dari pemerintah daerah Peraturan Gubernur Nomor 88 tahun 2020, padahal kebijakan sekolah/madrasah siaga bencana sudah ditetapkan pada tahun 2012. Dilihat dari sumber-sumber kebijakan untuk realisasi anggaran masih terbatas sehngga masih banyak sekolah rawan bencana yang belum mendapatkan pelatihan. Komunikasi antar organisasi dan badan-badan pelaksana pada saat berkoordinasi tidak begitu optimal, sosialisasi yang dilakukan baik pusat dan daerah belum sepenuhnya melibatkan unsur-unsur terkait seperti masyarakat tidak terlalu dilibatkan, sehingga masyarakat dengan perekonomian menengah ke bawah belum terlalu memahami kebijakan tersebut.

Karateristik badan-badan pelaksana memiliki antusias yang tinggi dan sangat mendorong terhadap pelaksanaan kebijakan baik dari segi pengajuan anggaran, dan pengadaan pelatihan di sekolah-sekolah rawan bencana.Kecenderungan pelaksana sudah berjalan dengan baik, terbukti banyaknya organisasi kemanusiaan yang ikut terlibat untuk mendorong pelaksanaan kebijakan sekolah/madrasah siaga bencana. Kondisi sosial ekonomi ditandai respon masyarakat dengan strata ekonomi menengah bawah memperlihatkan kurangnya antusiasme dan kecenderungan kurang peduli dengan tidak melibatkan diri pada program SMSB. Kebutuhan ekonomi sehari-hari dan beban hidup lainnya lebih menjadi perhatian dan perjuangan mereka untuk survive. 


\section{REFERENSI}

Amri, A., Bird,D.K. Ronan,K., Haynes,K., \& Towers,B. (2017). Disaster risk reduction education in Indonesia: Challenges and recommendations for scaling up. Natural Hazards and Earth System Sciences, 17(4) 595-612. https:// doi.org/10.5194/nhess17-595-2017.

Bev, J. \& Katrina (2010). Merapi and humanity. the Jakrta Post. Retrievedfromhttp://www.thejakartapost.com/news/2010/1 1/21/katrina-merapi-and-humanity.html.

BNPB (2014). Rencana Nasional Penanggulangan Bencana 20152019.Retrievedfromhttp://bnpb.go.id/dokumen/bukurenas-pb-pdf.

BNPB (2016). Indeks Risiko Bencana Indonesia (InaRISK). Jakarta.

Consortium Disaster Education (CDE). (2011). A Framework of School-Based Disaster Preparedness. CDE: Indonesia: 4-23.

Edward III, Goerge C. (1980). Implementing Public Policy . USA: Congressional Quarterly Inc.

Ostad Taghizadeh A, Hosseini M, Navidi I, Mahaki AA, Ammari H, Ardalan A. (2012). Knowledge, attitude, and practice of Tehran's inhabitants for an earthquake and related determinants. PLOS Curr. 2012;4:1-16.

Kemendikbud (2019). Pendidikan Tangguh Bencana: "Mewujudkan satuan Pendidikan Aman Bencana di Indonesia". https:/spabkemdikbud.go.id/wpcontent/uploads/2020/09/f inal_buku_SPAB_versi-2_bahasa_20DES.pdf

Lesmana, Purborini. Kesiapsiagaan Komunitas Sekolah Dalam Menghadapi Bencana Tsunami Di Kabupaten Magelang. Jurnal Tekhnik Sipil. 2015;1:1-14.

Moleong, Lexi J. (1998). Metode Penelitian Kualitatif. Cetakan Kesembilan. Bandung: PT. remaja Rosda Karya.

Miles, Matthew B dan A. Michael Huberman. (1992). Qualitative Data Analysis. Terjemahan Tjetjep Rohendi Rohidi. Jakarta:UI -Press.

Mukminin, Ferry A. (2019). Dibandingkan 2017, kejadian bencana di jawa barat pada 2018 lebih banyak. https://jabar.tribunnews.com (di akses 16 Januari 2021).

Muzenda-Mudavanhu, C. (2016). Jamba-Journal of Disaster Risk Studies Affiliation: A review of children's participation in disaster risk reduction. Jamba - Journal of Disaster Risk Studies, 8(1), 1-16. https://doi.org/10.4102/jamba

Peraturan Daerah Provinsi Jawa Barat Nomor 02 Tahun 2010 Tentang Penyelenggaraan Penanggulangan Bencana Daerah

Peraturan Kepala Badan Nasional Penanggulangan Bencana No 04 Tahun 2012 Tentang Pedoman Penerapan Sekolah/Madrasah Siaga Bencana.

Rachmalia MNS, Hatthakit U, Chaowalit A. Tsunami preparedness of people living in affected and non-affected areas: a comparative study in coastal area in Aceh Indonesia. Australasian Emergency Nursing Journal. 2011;14(1):17-25.

Rahman, F., \& Umam, Q. (2018). Sena Sakti ( Sekolah Bencana ; Siaga , Aksi dan Mitigasi ). Jurnal Ilmiah Ilmu Sosial, 4(1), 611.

Sakurai A, Bisri MBF, Oda T, et al. Exploring minimum essential for sustainable school disaster preparedness: a case of elementary school in Banda Aceh City, Indonesia. International Journal of Disaster Risk Reduction. 2018;29:73-83.

Suparman,N.(2017). Kualitas Pelayanan Izin Mendirikan Bangunan (IMB) Pada Badan Pelayanan Perizinan Terpadu dan Penanaman Modal (BPPTPM) Kabupaten Cianjur. Jurnal Borneo Administrato, Vol. 13 (1) pp. 41-56.

Suparman, N. (2019). Implementasi Kebijakan Pemungutan Pajak Hotel Atas rumah Kos di Kota Bandung. Kolaborasi: Jurnal Administrasi Publik. Vol. 5(3), pp. 304-318.

Undang - Undang Republik Indonesia No. 24 Tahun 2007 Tentang Penanggulangan Bencana.

Takahashi K, Kodama M, Gregorio ER, et al. (2015). School health: an essential strategy in promoting community resilience and preparedness for natural disasters. Disaster Resilience Promotion Strategy. ;8:1-3.

van Metter, Donald and Carl E. van Horn.(1975). " The Policy Implementation Process: A Conceptual Framework". Administration and Society, Vol 6 No. 4 February.

Winarno. (2016). Kebijakan Publik Era Globalisasi: Terori, Proses, dan Studi Kasus Komparatif. CAPAS (center of Academic publishing servive).

Zahro, Z. R., Andriningrum, H., Sari, E. P., \& Gunawan, I. (2014). Sekolah Siaga Bencana: Kajian Evaluatif Kesiapsiagaan Sekolah Menghadapi Bencana. Seminar Nasional Pendidikan, Fakultas Ilmu Pendidikan Universitas Negeri Malang. Sinergitas Keluarga, Sekolah Dan Masyarakat Dalam Penguatan Pendidikan Karakter, 511-519 